\title{
APPLICATION OF NEW MATERIALS DURING REHABILITATION OF ROAD STRUCTURES USING COLD RECYCLING TECHNOLOGY
}

\author{
KaterynaKrayushkina ${ }^{1}$, Tetiana Khimeryk ${ }^{2}$, Olena Oliynyk ${ }^{2}$, Liliia Gnatiuk ${ }^{2}$, Hanna Novik ${ }^{2}$ \\ ${ }^{1}$ M.P. Shulgin State Road Research Institute, DerzhdorNDI, Peremohy av. 57, 03113 Kiyv, \\ Ukraine, ekrayushkina15@ukr.net \\ 2 National Aviation University, NAU, Komarova av, 1, 01123 Kiyv, Ukraine,
}

\begin{abstract}
The economic attractiveness of cold recycling technology provides, first of all, the reuse of the existing material on the road for the arrangement of new pavement layers, so there is no need to equip special sites for the storage and disposal of old asphalt concrete. The essence of cold recycling technology which is most commonly used for arranging the subbase in Ukraine is that the defective and destroyed layers of road pavement are reinforced on-site by combined additives of organic and mineral binders. Cold recycling by complexity of works is divided into several types depending on the depth of milling. The choice of a rehabilitation type depends mainly on the general state of the pavement structure state which is determined before the beginning of repair work. In Ukraine, the main focus of R\&D in cold recycling technology is the use of new materials such as fiber - basalt or polymer, stabilizing additives, industrial waste - slag of various types of industries or other byproducts. Conducted research has shown that the use of organic and mineral mixtures from an optimal mix design with the introduction of basalt fibers increases the crack resistance and durability of the arranged subbase.
\end{abstract}

\section{Introduction}

Road repair and construction organizations in Ukraine annually perform big scopes of work to eliminate defects and deterioration of highways. Rehabilitation of pavement is carried out by different ways, methods and materials which jointly determine the lifetime, the cost and the quality, i.e. the efficiency of the repairs performed.

The main purpose of these works is to ensure safe and continuous traffic of motor vehicles with the given speeds [1].

\section{Statement of problem}

During the recent years in Ukraine, for arranging the non-rigid pavements, the cold recycling method was used on the basis of machines - a recycler, a concrete -water suspension preparation plant and a milling cutter [2]. 
Usage of the milling cutters allows milling the existing asphalt pavement resulting in the formation of so called asphalt crumbs.

The reclaimed mixture designed by the authors is used on the roads of Ukraine and includes asphalt crumb, cement, bituminous emulsion and basalt fiber in the volume of up to $5 \%$ of total mass of mixture.

\section{Main part}

The dispersion-reinforced mixture used in the study was obtained on the basis of recycled milled asphalt. The usage of basalt fiber improves the strength characteristics of asphalt mixture based pavements, increases the carrying capacity of pavement layers in 1.2-1.5 times and prolongs their lifetime by $40-50 \%$ [3].

The source material for basalt fiber is basalt rock which is a fine-grained, effusive raw material of volcanic origin. Basalt fiber is obtained by melting of basalt stone and drawing fiber from the resulting melt. The strength of basalt fiber with the diameter of 12-16 microns is $1500-2600 \mathrm{MPa}$, and the density is of $2.8-3.3 \mathrm{~g} / \mathrm{cm}^{3}$ respectively. The material is resistant to acids and alkalis. The optimal fiber length based on its even dispersion conditions in the mixture, is $20-25 \mathrm{~mm}$.

The general view of fiber is shown (see Fig. 1).

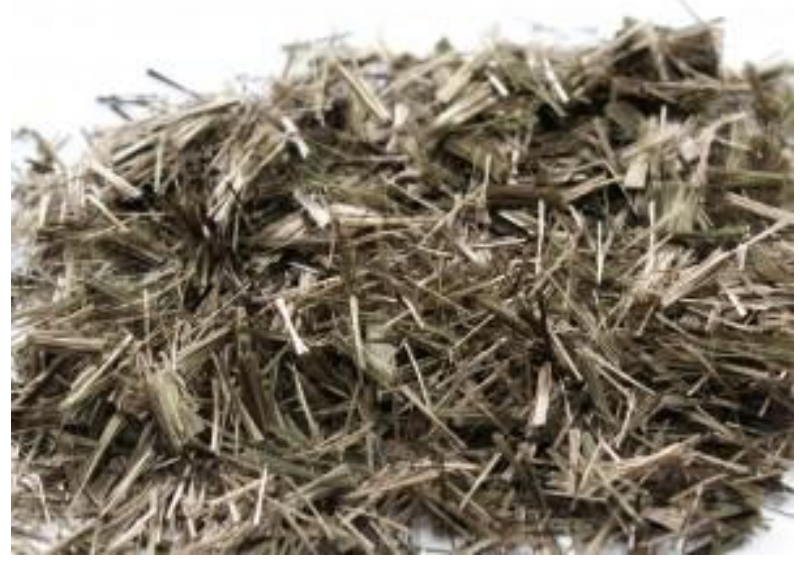

Fig. 1: Basalt fiber

Concrete mixture was prepared according to the following procedure: PC 400 cement, bitumen emulsion (cationic, of average decomposition) and fiber were added to the mixture of milled asphalt crumb, followed by thorough mixing. After preparing the samples at laboratory, the compaction load within the range from $20 \mathrm{MPa}$ to $40 \mathrm{MPa}$ was applied for approximately 3 minutes.

Schematic representation of the organic - mineral mixture with basalt fiber is shown (see Fig. 2). 


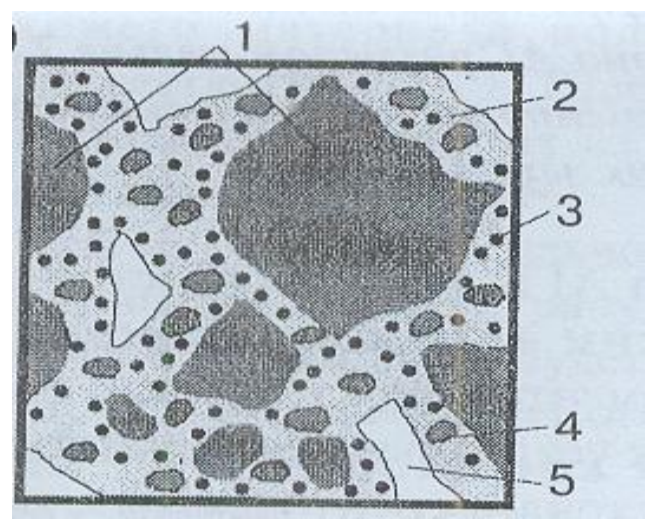

Fig. 2: Structure of dispersed-reinforced organic-mineral mixture

1- Asphalt crumb;

2- film of cement paste with the inclusion of droplets of emulsion bitumen;

3- basalt fiber;

4- grains of asphalt crumb with size less than $2 \mathrm{~mm}$;

5- air voids.

\section{Results of research}

According to the research [4], the application of basalt fiber reduces friction between the grains of asphalt granulate that improves the compaction of the reclaimed mixture, increases the number of inter-granular bonds and reduces the inter-granular voids that increases the density of the mixture and makes it possible to open traffic on the reclaimed layer almost immediately after compaction.

When the fiber is added to the organic-mineral mixture, a composite material is formed in which the matrix (binder) is significantly strengthened. Due to this the mixture has high bending strength.

It is known that the structure of the reclaimed mixture with the addition of bitumen emulsion (cationic) is formed over a sufficiently long time.

The application of basalt fiber accelerates the process of structure formation of such mixtures due to chemical interaction with bitumen droplets during the breakdown of emulsion.

Basalt fiber improves the electrostatic bonding of bitumen droplets with the surface of mineral grains and prevents their movement, increases the viscosity of the mixture and provides plastic-free flowing consistency.

The grading of the organic-mineral mixture using the bitumen emulsion as a binder and cement and basalt fiber is shown (see Fig. 3) [5]. 


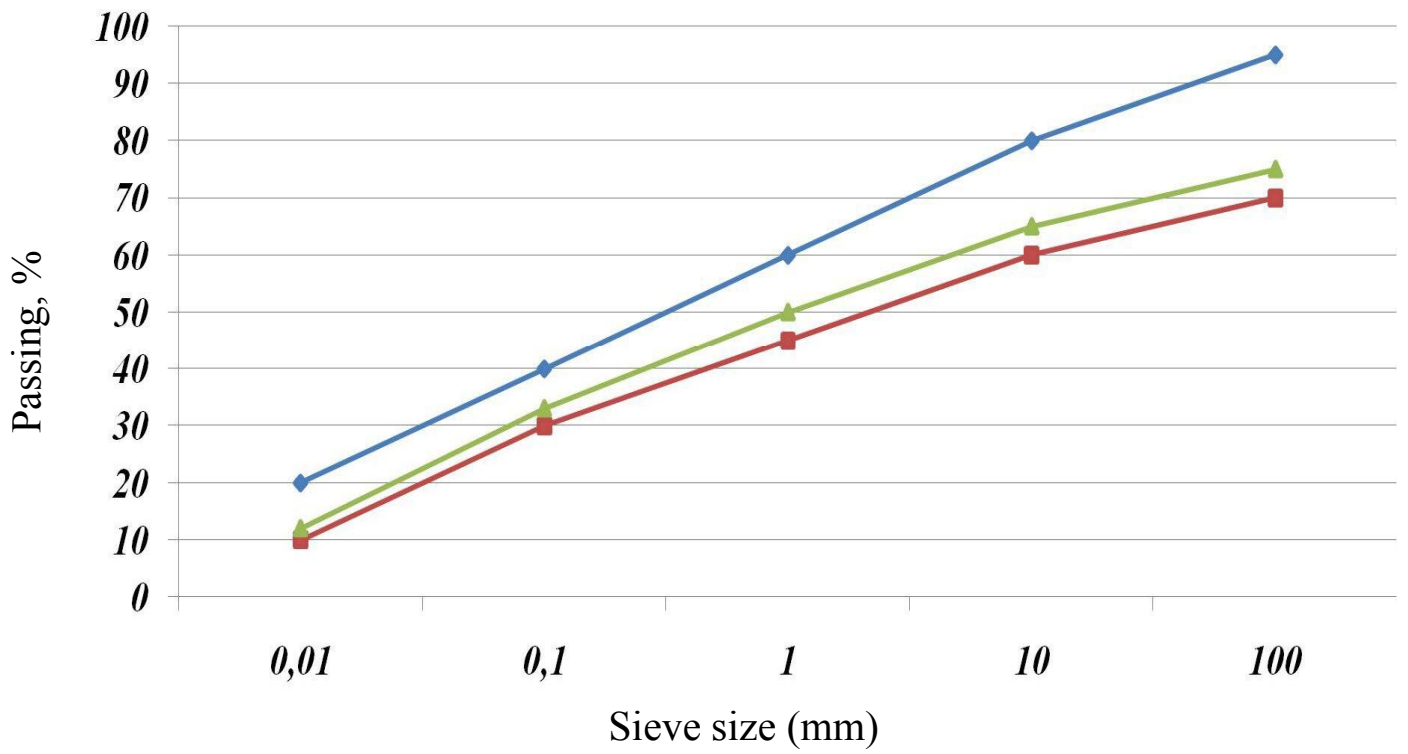

Fig. 3: Grain size distribution of the selected organic-mineral mixture

Physical and mechanical characteristics of the designed organic-mineral mixture with basalt fiber, depending on different degrees of compaction load, are given in Table 3.

Table 3: Physical and mechanical parameters of the organic-mineral mixture with basalt fiber

Type and consistency of the binder (4\% emulsion and $5 \%$ cement)

\section{Property}

Compaction load, MPa

\begin{tabular}{|c|c|c|c|}
\hline & 20 & 30 & 40 \\
\hline Average density, $\mathrm{g} / \mathrm{cm}^{3}$ & 2.240 & 2.26 & 2.39 \\
\hline Water saturation, $\%$ by mass & 7.1 & 6.2 & 4.8 \\
\hline Swelling, $\%$ by mass & 0.7 & 0.3 & \\
\hline $\begin{array}{l}\text { Compressive strength, } \mathrm{MPa} \text {, at th } \\
\text { temperature of: }\end{array}$ & & & \\
\hline $0^{\circ} \mathrm{C}$ & 7.6 & 8.3 & 8.7 \\
\hline $20^{\circ} \mathrm{C}$ & 3.4 & 3.7 & 3.9 \\
\hline $50^{\circ} \mathrm{C}$ & 1.1 & 1.3 & 1.4 \\
\hline Coefficient of short-term water resistance & 0.80 & 0.82 & 0.87 \\
\hline Coefficient of long-term water resistance & 0.83 & 0.87 & 0.89 \\
\hline
\end{tabular}

Analysis of the data indicates that the increase of the compaction load decreases the level of concrete water saturation, increase the average density, and increase the compressive strength and the water resistance coefficient (both, short-term and long-term). 
The optimal choice of the binder's quantity of cement, emulsion and basalt fiber was confirmed by determining the dependence of frost resistance coefficient on different quantity of binder, as shown (see Fig. 4).

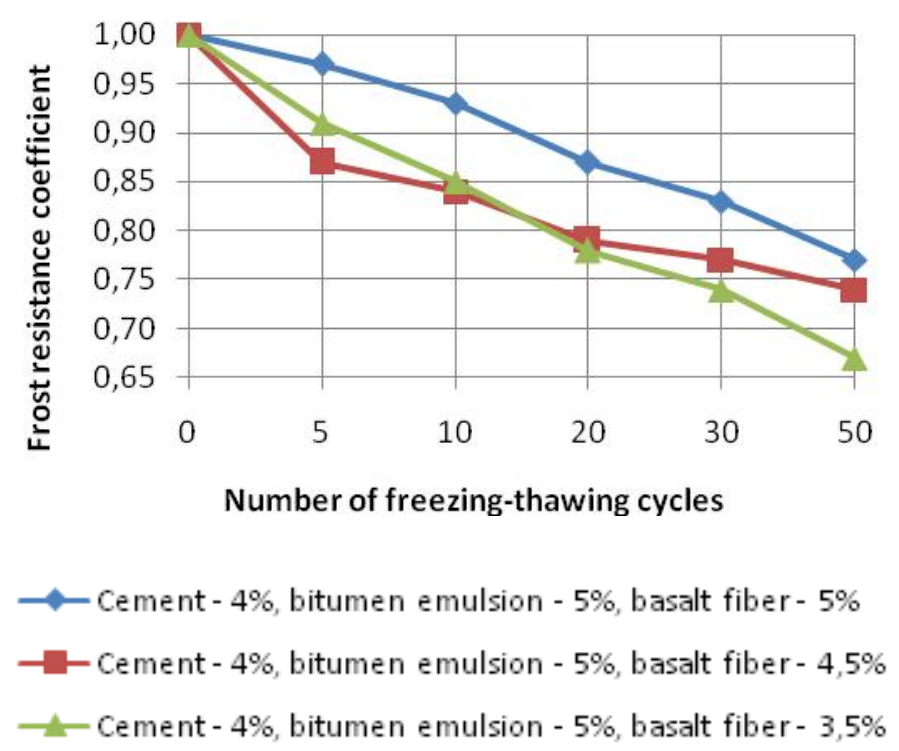

Fig. 4: Dependence of frost resistance coefficient on different quantity of binder

As it can be seen from the data shown in Figure $4[6-8]$, the organic-mineral mixture including $4 \%$ of cement, $5 \%$ of bitumen emulsion and $5 \%$ of basalt fiber corresponds to the highest values of frost resistance.

\section{Conclusions}

Thus, the use of organic-mineral mixtures of milled asphalt with basalt fiber is possible in the upper pavement layers of roads of all categories and significance, as well as ensuring the durability of the layer and the compliance of operating ability of roads with the requirements of traffic.

According to the results obtained in the research and on roads in operation, the application of basalt fiber provides durability and strength to the layer built with it during the inter-repair time.

\section{References}

[1] Ilchenko V.V. Restoration of pavement using cold milling technology / V.V. Ilchenko // Collection of scientific works (branch mechanical engineering, construction). Issue 18

(Poltava: PoltNTU, 2006).

[2] Draft Guidelines "Road pavement recycling". PIARC Version (August, 2002).

[3] Sasko M.F. Cold Recycling, Its Benefits and Prospects. Issue 2, Avtoshlyachovyk Road Worker of Ukraine, (2004). 37 - 40.

[4] Golovko S.K. Cold Recycling - Effective Pavement Rehabilitation Technology. Issue 6, Avtoshlyachovyk (Road Worker) of Ukraine, (2003) 34 - 35.

[5] Kostelev M.P. Cold Recycling Technology. Issue 3, Road technique, (2004). [Electronic resource]. - Access mode: http://library.stroit.ru. 
[6] Dolgilevich Yu.P. Experience in applying road pavement cold recycling technology in USA / Yu.P. Dolgilevich, M.P. Kostelev, Jan Hakkert // Road technique. (2005). Issue 1 [Electronic resource]. - Access mode: http://library.stroit.ru.

[7] Malyutin A. Technique for cold recycling / A.Malyutin // Funds. (2008). Issue 7 [Electronic resource]. - Mode of access: http://www.os1.ru.

[8] Livitina V.V. Cold recycling - an effective technology for the rehabilitation of asphalt pavement of airfields and highways / V.V Livitina, B.P. Mamontov, A.V Mitroshin // Bulletin of construction machinery. (2007). Issue 9 [Electronic resource]. - Access mode: http://stroy.dbases.ru. 